\title{
Homodinuclear Lanthanide Complexes with the Divergent Heterotopic 4,4'-bipyridine-N-oxide (bipyMO) Ligand
}

\author{
Lidia Armelao, ${ }^{[a, b]}$ Daniela Belli Dell'Amico, ${ }^{[c]}$ Luca Bellucci, ${ }^{[a, c]}$ Gregorio Bottaro, ${ }^{[b]^{*}}$ Samuele Ciattini, ${ }^{[\mathrm{d}]}$ \\ Luca Labella, ${ }^{[\mathrm{c}]^{*}}$ Giacomo Manfroni, ${ }^{[\mathrm{cc}}$ Fabio Marchetti, ${ }^{[\mathrm{c}]}$ Carlo Andrea Mattei ${ }^{[\mathrm{c}]}$ and Simona Samaritani ${ }^{[\mathrm{cc}]}$
}

\begin{abstract}
The synthesis of dinuclear molecular complexes $\left[\mathrm{Eu}_{2}(\mathrm{dbm})_{6}(\text { bipyMO })_{2}\right], \quad \mathbf{1 ,} \quad\left[\mathrm{Tb}_{2}(\mathrm{dbm})_{6}(\text { bipyMO })_{2}\right], \quad \mathbf{2}$, $\left[\mathrm{Eu}_{2}(\mathrm{tta})_{6}(\text { bipyMO })_{2}\right], \quad \mathbf{3} \quad\left[\mathrm{Eu}_{2}(\mathrm{hfac})_{6}(\text { bipyMO })_{3}\right], \quad \mathbf{4}$, $\left[\mathrm{Tb}_{2}(\mathrm{hfac})_{6}(\text { bipyMO })_{3}\right], \quad 5$ is here reported (bipyMO $=4,4^{\prime}-$ bipyridine- $\mathrm{N}$-oxide, $\mathrm{Hdbm}=$ dibenzoylmethane, $\mathrm{Htta}=$ thenoyltrifluoroacetone, Hhfac=hexafluoroacetylacetone). The products were obtained in mild conditions and with high yields reacting anhydrous lanthanide $\beta$-diketonates and bipyMO in 1:1 or 1.5 molar ratio in toluene. X-ray single crystal studies on $\mathbf{2 , 3}$, 4 showed that the heterotopic ligands are hypodentate, bridging the two lanthanide centres exclusively through the oxygen atom. Photoluminescence studies show bright red emissions from europium derivatives with absolute quantum yields up to $44 \%$.
\end{abstract}

\section{Introduction}

A library of divergent ligands is available for the preparation of coordination polymers (CPs) based on $d$ or $f$ metals. Among the neutral ditopic rigid ligands, the homotopic 4,4'-bipyridine (bipy) has been employed in a huge amount of complexes with $d$ metal centres $^{[1]}$ while $4,4^{\prime}$-bipyridine- $N, N$ '-dioxide (bipyDO) has been shown to be very effective in binding lanthanides. ${ }^{[2]}$ Conversely, the heterotopic divergent 4,4'-bipyridine- $N$-oxide (bipyMO, Scheme 1) has been scarcely used. ${ }^{[3]}$

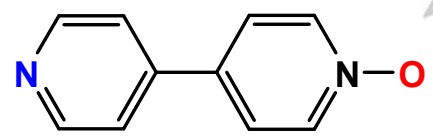

Scheme 1. 4,4'-bipyridine- $N$-oxide- (bipyMO)

In the literature, a few complexes have been reported where the bipyMO ligand behaves as connector producing homometallic CPs with metal centres belonging to the p-block $\left[\left(\mathrm{Pb}(\mathrm{II}),{ }^{[3 a, d]}\right.\right.$ $\left.\mathrm{Bi}(\mathrm{III})^{[3 \mathrm{c}]}\right]$ as well as to the d-block $[\mathrm{M}(\mathrm{II})=\mathrm{Mn}, \mathrm{Co}, \mathrm{Cu}$ and $\mathrm{Zn}] .{ }^{[4]}$ These polymers are characterized by the presence of two different regularly alternated coordination sites, $M^{*}[N]_{2}$ and $\mathrm{M}^{*}[\mathrm{O}]_{2},\left(\mathrm{M}^{*}\right.$ is the complementary metal coordination sphere and

[a] Dipartimento di Scienze Chimiche and INSTM, Università di Padova, via Marzolo 1,I-35131 Padova: Prof. L. Armelao, Dr. L. Bellucci

[b] CNR ICMATE and INSTM, Dipartimento di Scienze Chimiche, Università di Padova, via Marzolo 1, l-35131Padova: Prof. L. Armelao, Dr. G. Bottaro; E-mail: gregorio.bottaro@cnr.it

[c] Dipartimento di Chimica e Chimica Industriale, Università di Pisa, via Giuseppe Moruzzi 13, I-56124: Prof. D. Belli Dell'Amico, Prof F. Marchetti, Dr. G. Manfroni, Dr. C. A. Mattei, Prof. S. Samaritani, Prof L. Labella; E-mail:luca.labella@unipi.it

[d] Dipartimento di Chimica, Centro di Cristallografia Strutturale, Università degli Studi di Firenze, Polo Scientifico, Via della Lastruccia 3, I-50019 Sesto Fiorentino: Dr. S. Ciattini
[N] and [O] specify the donor atom of the connector). Heterometallic CPs have been prepared for $3 \mathrm{~d}[\mathrm{M}(\mathrm{II})-\mathrm{M}$ '(II) = $\mathrm{Mn}-\mathrm{Cu}]^{[4]}$ or for $3 \mathrm{~d}-4 \mathrm{f}$ metal centres $[\mathrm{Ln}(\mathrm{III})=\mathrm{Eu}, \mathrm{M}(\mathrm{II})=\mathrm{Cu}, \mathrm{Zn}$; $\mathrm{Ln}(\mathrm{III})=\mathrm{Dy}, \mathrm{M}(\mathrm{II})=\mathrm{Co} .^{[5]}$ In these heterometallic polymers the perfect alternation of the coordination sites $\left(\mathrm{Cu}^{*}[\mathrm{~N}]_{2}\right.$ and $\mathrm{Mn}^{*}[\mathrm{O}]_{2}$ or $\mathrm{M}^{*}[\mathrm{~N}]_{2}$ and $\mathrm{Ln}^{*}[\mathrm{O}]_{2}$ ) showed the efficient discrimination operated by bipyMO.

On the other hand, examples of complexes with terminal hypodentate ligands bipyMO $(\mathrm{N}-$ or O-coordinated in dependence of the metal ion identity) are known. In these species the uncoordinated site ( $\mathrm{O}$ or $\mathrm{N}$, respectively) is engaged in hydrogen bonding, usually with water. ${ }^{[6]}$ Nevertheless, in the mononuclear platinum(II) derivative $\left[\mathrm{PtCl}_{2}\left(\mathrm{PPh}_{3}\right)(\right.$ bipyMO)], the hypodentate $\mathrm{N}$-coordinated ligand does not show significant interactions of the O-site with other groups and the complex was successfully used as a metallo-ligand. ${ }^{[4]}$

With the intent to extend our synthetic studies ${ }^{[4,5]}$ on the coordination chemistry of the bipyMO ligand, its reactivity of the bipyMO ligand towards oxophylic open metal sites, as in [ $\operatorname{Ln}(\beta-$ dik)3], appeared quite attractive. In this paper we report the synthesis of $\mathrm{Eu}_{2}(\mathrm{dbm})_{6}(\text { bipyMO })_{2}$ 1, $\mathrm{Tb}_{2}(\mathrm{dbm})_{6}(\text { bipyMO })_{2} 2$, $\mathrm{Eu}_{2}(\mathrm{tta})_{6}\left(\right.$ bipyMO) $3 \mathrm{Eu}_{2}(\text { hfac })_{6}(\text { bipyMO) })_{3} 4, \mathrm{~Tb}_{2}(\text { hfac })_{6}(\text { bipyMO) })_{3}$ (5) $(\mathrm{Hdbm}=$ dibenzoylmethane, $\mathrm{Htta}=$ thenoyltrifluoroacetone, Hhfac=hexafluoroacetylacetone). In these dinuclear complexes each bipyMO shows a new hypodentate coordination mode, bridging two metal ions through the oxygen atom. This $\mu-O$ coordination mode allows the achievement of the typically high lanthanide coordination numbers without the involvement of the bipyMO nitrogen donor functionality.

\section{Results and Discussion}

The reactions between the lanthanide $\beta$-diketonato complexes $\left[\mathrm{Ln}(\mathrm{dbm})_{3}\right](\mathrm{Ln}=\mathrm{Eu}, \mathrm{Tb})$ with bipyMO, carried out with $1: 1$ or $1: 2$ molar ratio in anhydrous toluene at about $100{ }^{\circ} \mathrm{C}$, afforded smoothly and in high yields the derivatives 1 and 2 with composition [ $\mathrm{Ln}(\mathrm{dbm})_{3}($ bipyMO)]. Recrystallization in toluene at low temperature produced crystals of the solvated products that collapsed in air or under vacuum with loss of the crystallization solvent. Although the formulae could match with that expected for coordination polymers based on bipyMO as connector, a X-ray diffraction study on single crystals of $2 \cdot \mathrm{nC}_{7} \mathrm{H}_{8}$ established that the product was formed by $\left[\mathrm{Tb}_{2}(\mathrm{dbm})_{6}(\text { bipyMO })_{2}\right]$ dinuclear molecules where bipyMO acted as a bridging ligand via its oxygen atom $(\mu-O)$, leaving uncoordinated the nitrogen atom. Analytical data and IR spectra strongly suggest a similar molecular structure for the europium derivative. An analogous result was obtained with the reaction between $\left[\mathrm{Eu}(\mathrm{tta})_{3}\right]$ and bipyMO carried out in anhydrous toluene, affording in good yield the dinuclear $\left[\mathrm{Eu}_{2}(\mathrm{tta})_{6}(\text { bipyMO })_{2}\right], 3$. For 3 single crystals suitable for XRD 
studies were obtained by pentane diffusion in a toluene solution of the product; in this case the crystals did not contain crystallization solvent and did not collapse by treatment under vacuum.

The molecular structure of $\mathbf{2}$ is shown in Figure 1. The coordination geometry for terbium is that of a dodecahedron with triangular faces $\left(D_{2 d}\right)$, (Figure 2) a rather common geometry for eight-coordinated lanthanide complexes. ${ }^{[7]}$ The molecule is centrosymmetric, the inversion centre being placed in the middle of the oxygen atoms of the two bipyMO ligands. The segment 01...01' represents the shared edge between the two coordination dodecahedra. Table 1 reports selected bond distances and angles of the coordination polyhedron.

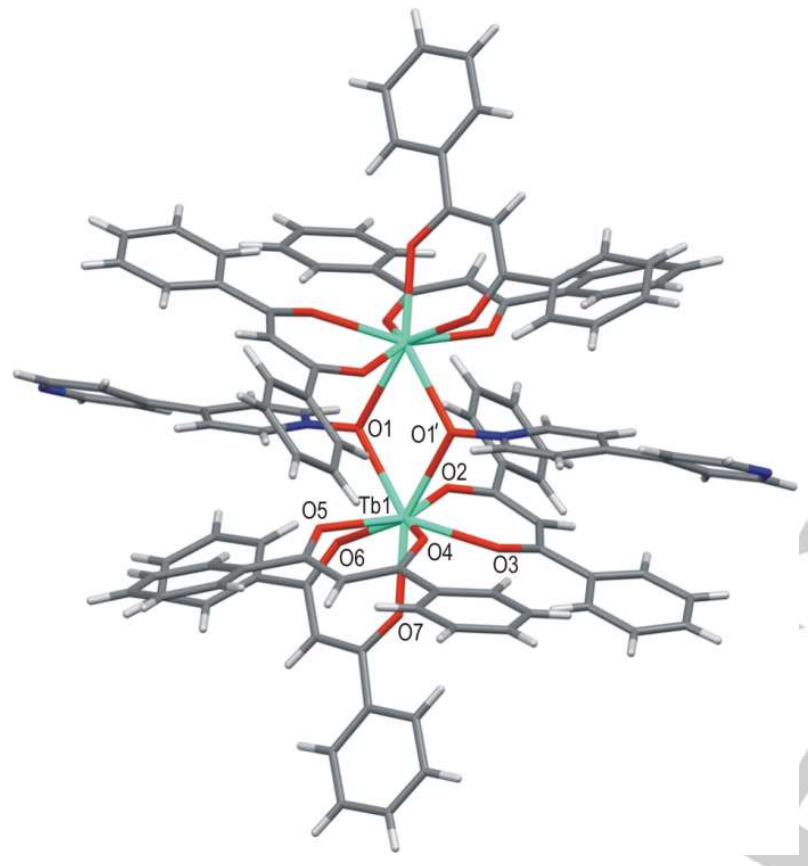

Figure 1. Molecular structure of 2 . ' $^{\prime} 1-x, 1-y, 1-z$

Table 1. Comparison between coordination polyhedra of eight-coordinated lanthanides.

\begin{tabular}{|c|c|c|}
\hline$d[\AA], \quad$ angle $\left[{ }^{\circ}\right]$ & $2[\mathrm{~Tb}]$ & $3[\mathrm{Eu}]$ \\
\hline Ln-01, 01-Ln-01' & $2.486(3), 62.18(12)$ & $2.469(5), 61.18(15)$ \\
\hline Ln-01', O2-Ln-03 & $2.440(4), 71.66(13)$ & $2.470(4), \quad 71.10(19)$ \\
\hline Ln-02, 04-Ln-05 & $2.345(4), 70.51(12)$ & $2.377(5), \quad 70.08(16)$ \\
\hline Ln-03, 06-Ln-07 & $2.341(4), 72.96(13)$ & $2.378(4), 71.33(16)$ \\
\hline Ln-04 & $2.334(4)$ & $2.366(4)$ \\
\hline Ln-05 & $2.364(4)$ & $2.381(5)$ \\
\hline Ln-06 & $2.348(3)$ & $2.373(5)$ \\
\hline Ln-07 & $2.300(4)$ & $2.379(5)$ \\
\hline
\end{tabular}

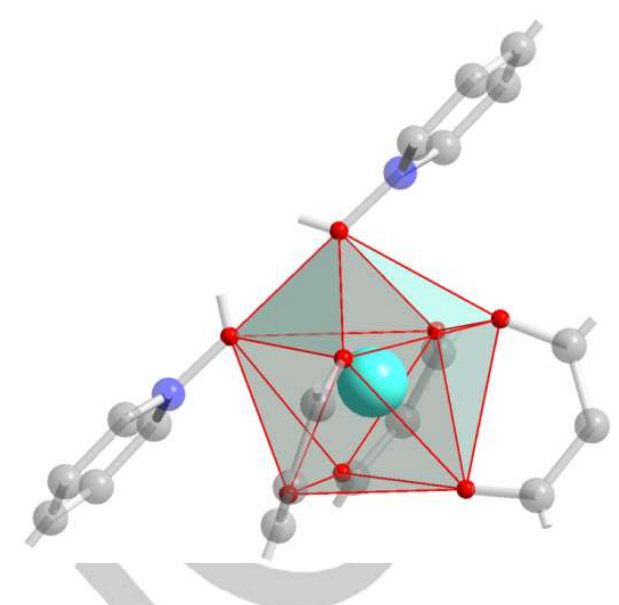

Figure 2. The geometry of the metal coordination in $\mathbf{2}$ and $\mathbf{3}$.

The molecular structure of $\mathbf{3}$ is shown in Figure 3 . Notwithstanding many differences, as the nature of the metal centre and of the diketonato ligand, the structure of $\mathbf{3}$ is quite similar to that of $\mathbf{2}$ as it can be seen comparing the corresponding geometrical parameters of the two molecules (Table 1). The smaller ionic radius of $\mathrm{Tb}^{3+}$ with respect to $\mathrm{Eu}^{3+}$ is related to the lower mean distance $\mathrm{Tb}-\mathrm{O}(2.37 \AA)$ with respect to the mean Eu-O distance $(2.40 \AA)$.

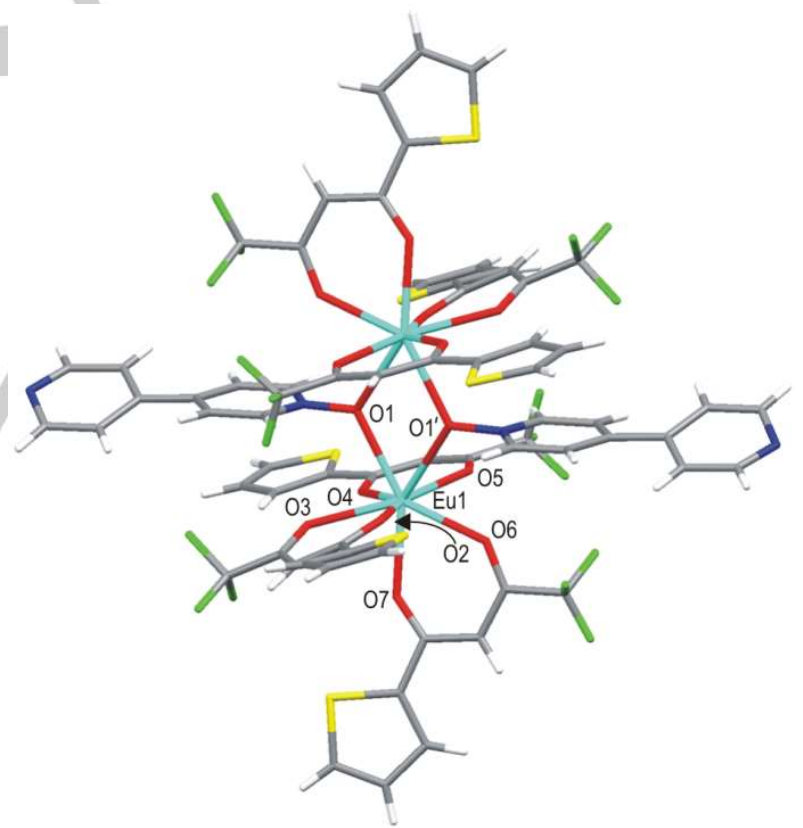

Figure 3. Molecular structure of 3 . Only the most populated positions of disordered $\mathrm{CF}_{3}$ groups have been represented. ' $=1-x, 1-y, 2-z$.

The experimental Powder X-Ray Diffraction Pattern of $\mathbf{3}$ is reported in Figure 4, compared with the calculated one obtained by single crystal data. 


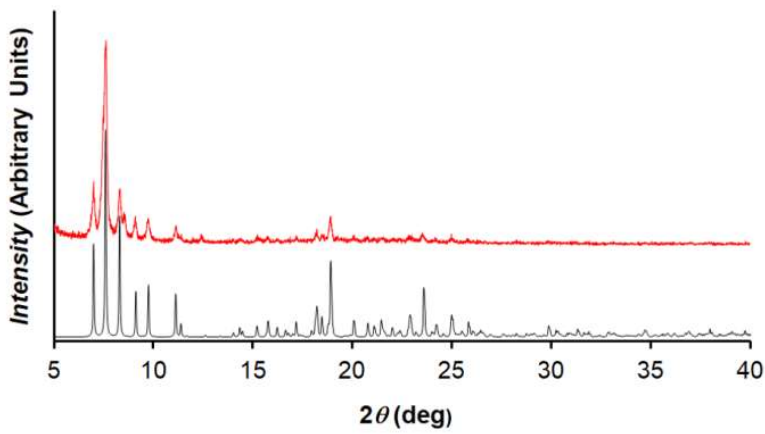

Figure 4. PXRD patterns of $\mathbf{3}$ (red: experimental, black: calculated).

The observed bridging coordination mode is unprecedented for bipyMO since elsewhere the oxygen atom of the ligand is bonded only to a single metal centre. This new coordination mode could be anticipated from the coordination chemistry of the homotopic spacer 4,4'-bipyridine-N,N'-dioxide (bipyDO, Scheme 2). As a matter of fact, coordination polymers based on the bipyDO spacer may have each of the two oxygen atoms of the connector coordinated in a terminal mode to one lanthanide ion, ${ }^{[8,9,10]}$ or bridging two metal ions and creating dinuclear units as nodes in $1 \mathrm{D} \mathrm{CPs}$ as in $\left\{\left[\mathrm{Eu}_{2}(\mathrm{bta})_{6}(\mathrm{bipyDO})\right]\right\}_{n}(\mathrm{Hbta}=$ benzoyltrifluoroacetone $)^{[10 \mathrm{~d}]}$ or in the $3 \mathrm{D} \mathrm{CPs}$ $\left\{\left[\mathrm{La}_{2}(\mathrm{bta})_{6}(\text { bipyDO })_{1.5}\right] \cdot 1.5 \mathrm{H}_{2} \mathrm{O}\right\}_{n}^{[10 \mathrm{cc}]}$ and $\left\{\left[\mathrm{Ln}_{2}(\mathrm{hfac})_{6}(\text { bipyDO })_{1,5}\right]\right\}_{n}$ $(\mathrm{Ln}=\mathrm{Eu}, \mathrm{Gd}, \mathrm{Dy}) .^{[10 \mathrm{e}]}$

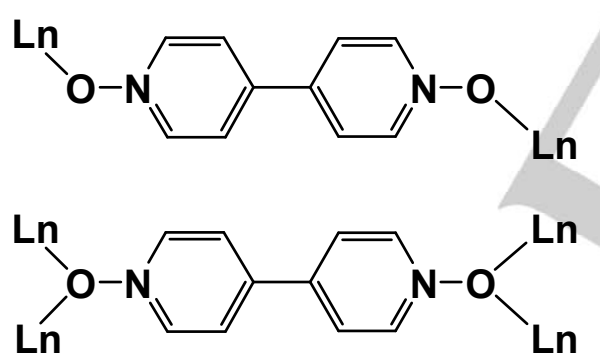

Scheme 2. Two possible bridging coordination modes of the bipyDO ligand.

Steric or electronic reasons could be proposed to justify this outcome, nevertheless the variability of the lanthanide coordination number can play a role. Indeed it is useful to recall here that molecular dinuclear species with the monodentate pyridine-N-oxide (pyNO), have been reported both as [ $\left.\left.\mathrm{Ln}_{2}(\mathrm{hfac})_{6}(\mathrm{pyNO})_{n}\right)\right]$ complexes with $n=2(\mathrm{Ln}=\mathrm{Eu}, \mathrm{Gd}, \mathrm{Tb}, \mathrm{Dy})$ ${ }^{[11]}$ or with $n=3(\mathrm{Ln}=\mathrm{Gd}, \mathrm{Dy}){ }^{[10 \mathrm{e}]}$ where the lanthanide ions show respectively a coordination number 8 or 9 , being bridged by two or three pyNO ligands.

Present results confirm that the preference of the lanthanide centres for oxygen donor ligands drives the self-assembling of their derivatives. Elsewhere, the hypodentate coordination mode of the bipyMO ligand was related to the presence of strong hydrogen bonding interactions, resulting in a complex supramolecular net. In complexes $\mathbf{2}$ and 3, prepared in anhydrous conditions and soluble in toluene, no hydrogen bonding interaction competes with the coordination to a metal.

The reactions between $\left[\mathrm{Ln}(\mathrm{hfac})_{3}\right](\mathrm{Ln}=\mathrm{Eu}, \mathrm{Tb})$ and bipyMO were carried out in anhydrous toluene and, at variance with the syntheses discussed above, complexes $\mathbf{4}$ and $\mathbf{5}$ were obtained where the Ln:bipyMO molar ratio was $2: 3$. Single crystals were obtained by cooling (at about $-30^{\circ} \mathrm{C}$ ) toluene solutions of the products. X-ray diffraction studies on 4.3 toluene showed dinuclear molecules with nine-coordinated europium ions through three $\mu_{2}$-O-bridging bipyMO ligands. The coordination geometry around europium is tricapped trigonal prismatic (Figure 5). Cell parameters on a single crystal of $\mathbf{5}$ showed it to be isostructural with the europium derivative.

The molecular structure of $\mathbf{4}$ is shown in Figure 6. At variance with the molecules described so far, it does not possess any symmetry element, although a pseudo mirror passing through 04, 07 and 08 approximately relates the two halves of the molecule. Both independent europium atoms are in a tricapped trigonal prismatic coordination, the two polyhedra sharing the face 04, 07, 08. Some geometrical parameters of the coordination polyhedron are listed in Table 2.
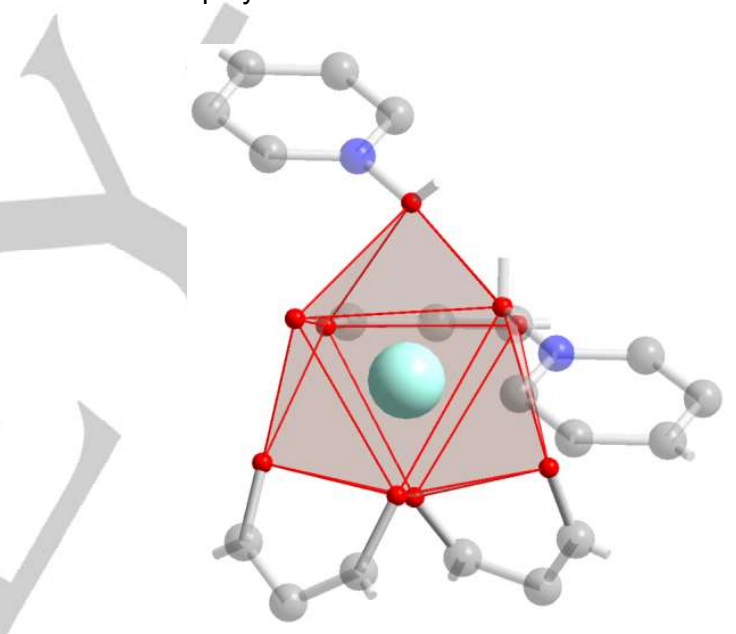

Figure 5. Coordination geometry around the metal in 4. 


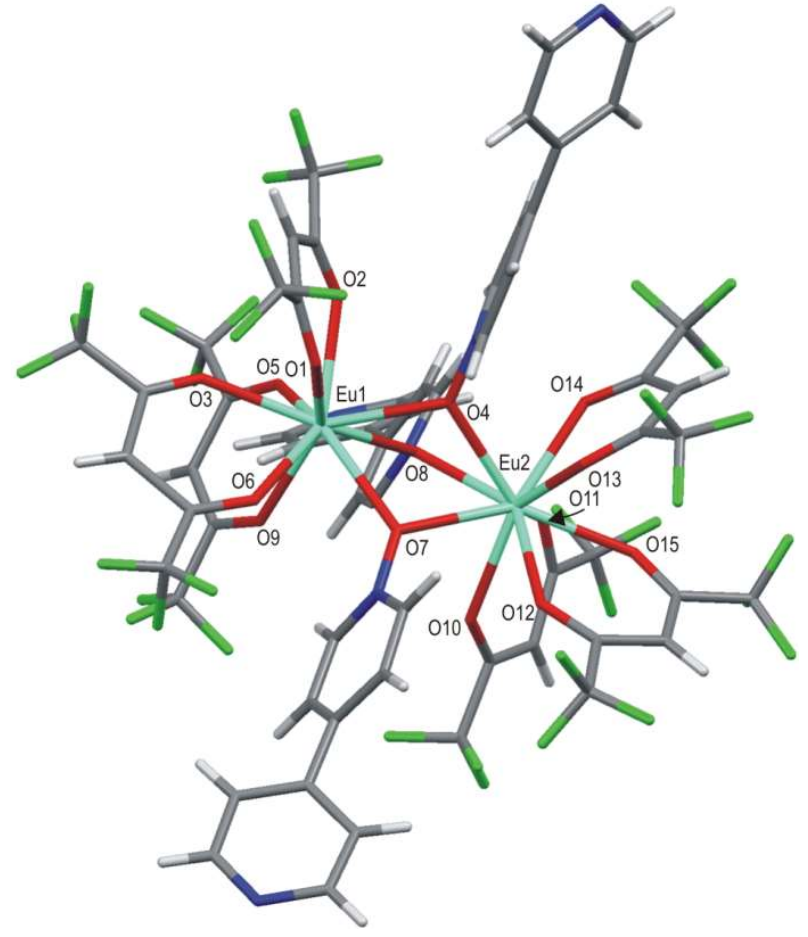

Figure 6. Molecular structure of 4 . Only the most populated positions of disordered $\mathrm{CF}_{3}$ groups have been represented.

Table 2. Selected bond distances for $4 \cdot 3$ toluene $(\AA)$.

\begin{tabular}{llll}
\hline Eu1-01 & $2.434(5)$ & Eu2-07 & $2.454(5)$ \\
Eu1-02 & $2.399(4)$ & Eu2-08 & $2.446(5)$ \\
Eu1-03 & $2.374(6)$ & Eu2-010 & $2.412(4)$ \\
Eu1-04 & $2.473(5)$ & Eu2-04 & $2.505(4)$ \\
Eu1-05 & $2.452(5)$ & Eu2-011 & $2.451(4)$ \\
Eu1-06 & $2.419(5)$ & Eu2-012 & $2.431(5)$ \\
Eu1-07 & $2.481(5)$ & Eu2-013 & $2.421(5)$ \\
Eu1-08 & $2.481(5)$ & Eu2-014 & $2.390(4)$ \\
Eu1-09 & $2.414(5)$ & Eu2-015 & $2.379(5)$ \\
\hline
\end{tabular}

Therefore, with all the diketonates we used, the assemblage of $\left[\mathrm{Ln}(\beta-\mathrm{dik})_{3}\right]$ with bipyMO proceeds with formation of dinuclear molecules where only the oxygen atom of the divergent ligand is engaged in the coordination to the metal ion. With bipyMO ligands, nitrogen functionalities do not appear able to coordinate the lanthanide metal, although bipy has been used as exclusive spacer in 1D polymers having neutral lanthanide diketonate complexes as nodes. ${ }^{[12]}$

$\mathrm{Eu}^{3+}$-based dinuclear complexes 1, 3 and 4 can be classified considering how many divergent bipyMO ligands connect two europium centers, as well as the $\mathrm{Eu}^{3+}$ coordination number $(\mathrm{CN})$. Noteworthy, $\mathrm{Eu}^{3+}$ has $\mathrm{CN} 9$ only in hfac containing complexes. As sketched in Figure 7, we can find from two to three bridging ligands depending how they coordinate to $\mathrm{Eu}^{3+}$ ions. The drawings in Figure 7 serve as a quick eye guide to correlate the dimers structure with their luminescence properties.
Upon irradiation, compounds 1, 3 and $\mathbf{4}$ emit bright red light also detectable at the naked eye. The corresponding photoluminescence $(\mathrm{PL})$ spectra show the characteristic sharp bands associated to ${ }^{5} \mathrm{D}_{0} \rightarrow{ }^{7} \mathrm{~F} \mathrm{~J}(\mathrm{~J}=0-4)$ transitions of $\mathrm{Eu}^{3+}$ ions (Figure 9 and 10). ${ }^{[13]}$

Europium emission can be excited in a wide wavelength range, from UV to visible, up to $490 \mathrm{~nm}$ for 1 and 3 that have $\beta$ diketonato ligands containing aromatic moieties (Figure 8). Conversely, hfac-based dinuclear complexes can be excited up to $450 \mathrm{~nm}$.

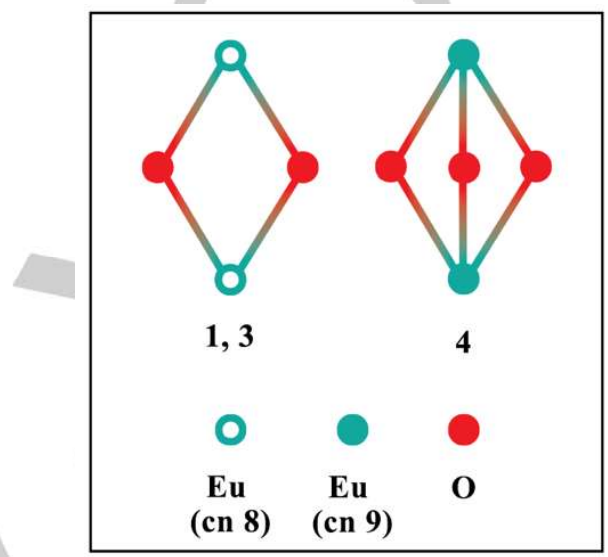

Figure 7. Schematic representation of the connections between two $\mathrm{Eu}^{3+}$ ions in the luminescent dinuclear complexes 1, 3 and 4.

The sensitized emission is achieved thanks to the absorption properties of the ligands, according to the following steps: (i) absorption of light, (ii) intersystem crossing (ISC) from the singlet $(\mathrm{S})$ to the triplet $(\mathrm{T})$ level, (iii) energy transfer from the chromophore to the lanthanide cation. ${ }^{[14]}$

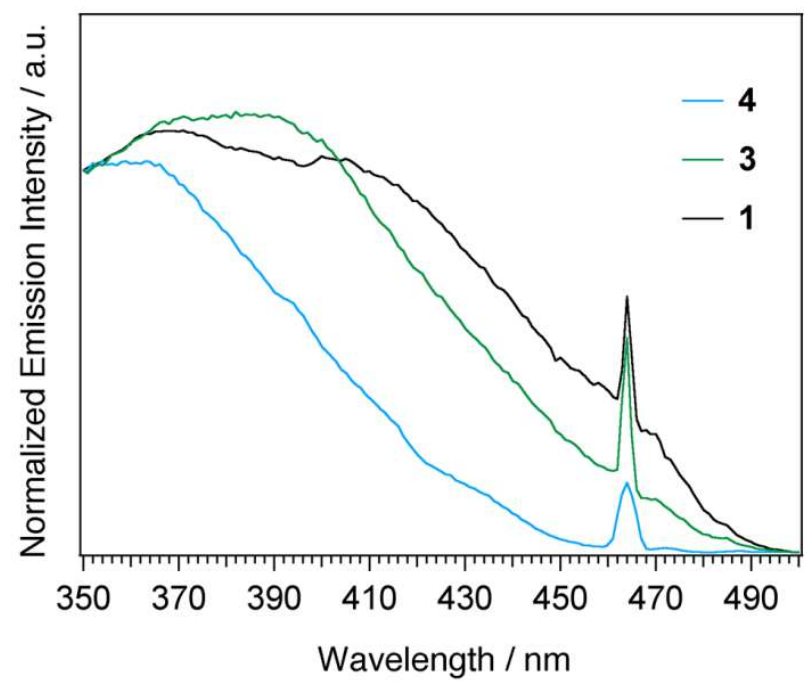

Figure 8. Excitation spectra monitored at $612 \mathrm{~nm}$. 
As it is typical in $\mathrm{PL}$ spectra of $\mathrm{Eu}^{3+} \beta$-diketonato complexes, compounds $\mathbf{1}, \mathbf{3}$ and $\mathbf{4}$ present a strong hypersensitive ${ }^{5} \mathrm{D}_{0} \rightarrow{ }^{7} \mathrm{~F}_{2}$ transition which is ca. one order of magnitude more intense than the ${ }^{5} D_{0} \rightarrow{ }^{7} F_{J}, J=1,3$ and 4 emissions.

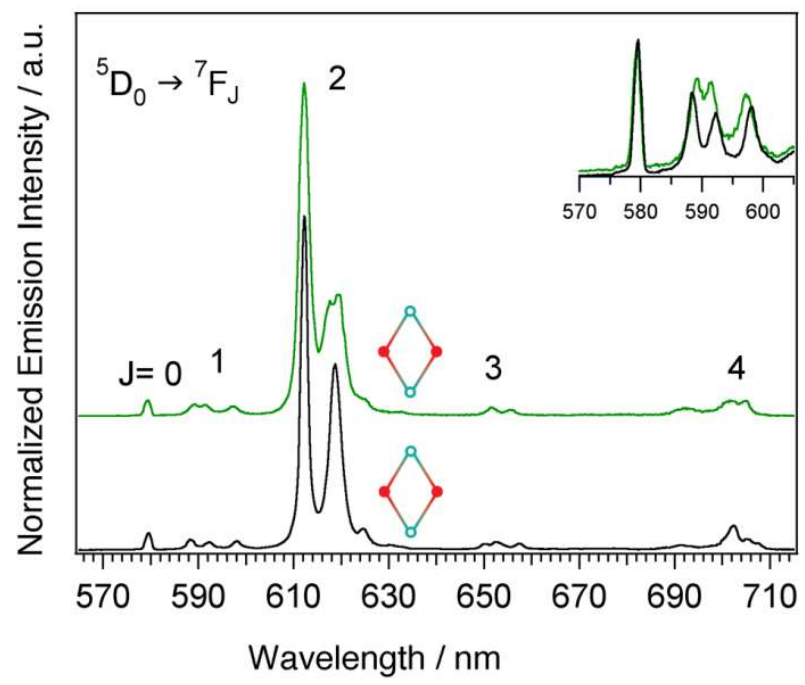

Figure 9. PL spectra of compounds 1 (black curve) and 3 (green curve) excited at $350 \mathrm{~nm}$. Inset: enlargement of the region of ${ }^{5} \mathrm{D}_{0} \rightarrow{ }^{7} \mathrm{~F}_{0}$ and ${ }^{5} \mathrm{D}_{0} \rightarrow{ }^{7} \mathrm{~F}_{1}$ transitions.

It is worth noting that compounds with the same crystallographic structure present also similar photoluminescence features. For example, PL spectra of the octacoordinated compounds 1 and 3 (Figure 9) have almost the same shape for the ${ }^{5} D_{0} \rightarrow{ }^{7} F_{2}$ transition, characterized by two strong and well resolved peaks at 612.4 and $618.8 \mathrm{~nm}$, and a low intensity shoulder at $624.6 \mathrm{~nm}$ Similar considerations apply to ${ }^{5} D_{0} \rightarrow{ }^{7} F_{1}$ (Figure 9 inset) whose degeneration is completely removed due to the low symmetry. ${ }^{[13]}$ Small variations were instead observed for the crystal field components of the ${ }^{5} \mathrm{D}_{0} \rightarrow{ }^{7} \mathrm{~F}_{4}$ multiplets.

In the nonacoordinated bipyMO complex 4 , the ${ }^{5} \mathrm{D}_{0} \rightarrow{ }^{7} \mathrm{~F}_{2}$ transition is still the most intense but it appears as a single sharp peak with a shoulder on the long wavelength side (Figure 10). Since ${ }^{5} D_{0}$ and ${ }^{7} F_{0}$ levels are both non degenerate, on the basis of single crystal $\mathrm{X}$-ray diffraction of compound $\mathbf{4}$ that shows two independent europium atoms in a tricapped trigonal prismatic coordination, two peaks might be expected for the ${ }^{5} D_{0} \rightarrow{ }^{7} F_{0}$ transition. However, the number of observed ${ }^{5} D_{0} \rightarrow{ }^{7} F_{0}$ transitions does not always correspond to the number of independent (crystallograpically) europium sites. In fact, the ${ }^{5} \mathrm{D}_{0} \rightarrow{ }^{7} \mathrm{~F}_{0}$ transition is silent in all but $C_{n v}, C_{n}$ and $C_{s}$ symmetries, and hence the determination of the number of crystal sites from ${ }^{5} D_{0}$ $\rightarrow{ }^{7} \mathrm{~F}_{0}$ analysis is not unambiguous. ${ }^{[13]}$ In the present case, ${ }^{5} \mathrm{D}_{0} \rightarrow$ ${ }^{7} \mathrm{~F}_{0}$ analysis does not allow to discriminate between the two sites.

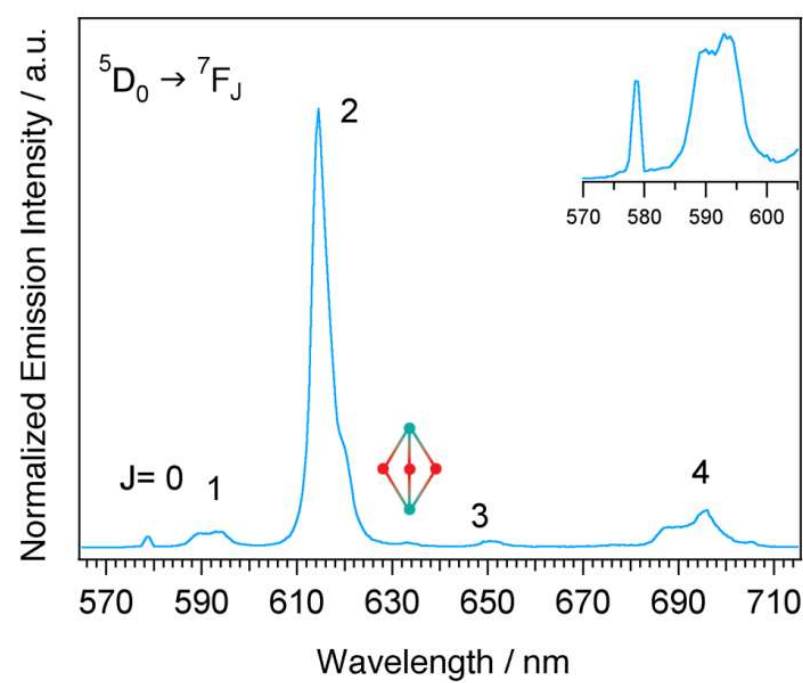

Figure 10. PL spectra of 4 excited at $350 \mathrm{~nm}$. Inset: enlargement of the region of ${ }^{5} \mathrm{D}_{0} \rightarrow{ }^{7} \mathrm{~F}_{0}$ and ${ }^{5} \mathrm{D}_{0} \rightarrow{ }^{7} \mathrm{~F}_{1}$ transitions.

${ }^{5} D_{0}$ lifetime values progressively increased from 0.46 to $0.67 \mathrm{~ms}$ by changing the nature of $\beta$-diketonato ligand in the order $\mathrm{dbm}<$ $\mathrm{tta}<\mathrm{hfac}$ (Table 3) in compounds 1, 3 and $\mathbf{4}$. A useful parameter calculated from europium emission spectra is the radiative lifetime $\left(\tau_{\text {rad }}\right.$, Eq. 1$)$, i.e. the luminescence lifetime of the level in the absence of non-radiative processes. ${ }^{[13]}$

$$
\frac{1}{\tau_{\text {rad }}}=A_{M D, 0} n^{3}\left(\frac{I_{\text {tot }}}{I_{M D}}\right)
$$

The lifetime of an excited state depends from the balance between the probability for radiative and non-radiative deactivation processes. The non-radiative relaxations cannot be directly observed and information about them can be achieved only by comparing the experimental excited state lifetimes and the radiative lifetimes. The difference between their values is attributed to the occurrence of non-radiative relaxations. In equation $1, A_{M D, 0}$ is the spontaneous emission probability in vacuum of the ${ }^{5} D_{0} \rightarrow{ }^{7} F_{1}$ transition and its value is $14.65 \mathrm{~s}^{-1}$. I tot and $I_{M D}$ are the integrated areas of the whole emission spectrum and of the ${ }^{5} D_{0} \rightarrow{ }^{7} F_{1}$ transition, and $n$ is the refractive index. ${ }^{[13]}$

Radiative lifetimes can be used to calculate the intrinsic quantum yield $(\Phi$, Table 3 ) which gives the ratio between the radiative and the experimental lifetimes (Eq 2).

$$
\Phi=\frac{\tau_{o b s}}{\tau_{\text {rad }}}
$$

$\Phi$ should not be confused with the photoluminescence quantum yield (PLQY, Table 3), i.e. an experimentally evaluated quantity given by the ratio of the number of emitted photons and the number of absorbed ones for which the following relation is valid $P L Q Y \leq \Phi$. 
Table 3. Experimental lifetimes $(\tau)$, radiative lifetimes $\left(\tau_{\text {rad }}\right)$, absolute quantum yields (PLQY), intrinsic quantum yields $(\Phi)$ and sensitization efficiency $(\eta)$ for compounds 1, 3 and 4 . In the second column is reported the lanthanide coordination number $(\mathrm{CN})$.

\begin{tabular}{ccccccc}
\hline CN & $\tau(\mathrm{ms})$ & $\begin{array}{c}{ }^{\mathrm{b}} \tau_{\text {rad }} \\
(\mathrm{ms})\end{array}$ & $\begin{array}{c}\text { PLQY } \\
(\%)\end{array}$ & $\Phi(\%)$ & ${ }^{\mathrm{a}} \eta(\%)$ \\
\hline $\mathbf{1}$ & 8 & 0.45 & 0.90 & 26 & 50 & 52 \\
$\mathbf{3}$ & 8 & 0.58 & 1.02 & 44 & 57 & 77 \\
$\mathbf{4}$ & 9 & 0.65 & 1.02 & 40 & 66 & 61 \\
\hline
\end{tabular}

${ }^{a}$ Sensitization efficiency is calculated with the following formula: $\eta=P L Q Y / \Phi$ ${ }^{\mathrm{b}}$ For the calculation of radiative lifetimes we used a refractive index of 1.5 for the solid complexes. ${ }^{[13]}$

Europium PLQY values are higher than $20 \%$ for all dinuclear complexes and both octa- and nonacoordinated dimers achieve $\eta \geq 50 \%$ (Table 3). Conversely, the low PLQY and $\eta$ values for 1 are not related to its structure being the same of $\mathbf{3}$ for which these parameters are quite intense. Even though $\mathrm{dbm}$ and tta are able to sensitize europium luminescence, the absence of fluorinated substituents on dbm explains the lower PLQY value for complex 1, compared to its structural analogue 3 . In fact, fluorinated substituents on the $\beta$-diketonato ligand, like in $\mathbf{3}$, increase the PLQY of the complex. ${ }^{[15]}$

We synthesized also $\mathrm{Tb}^{3+}$ complexes with $\mathrm{dbm}(\mathbf{2})$ and hfac (5) both having bipyMO as spacer. Due to the energy of dbm triplet levels $\left(21200 \mathrm{~cm}^{-1}\right),{ }^{[16]}$ nearly resonant with $\mathrm{Tb}^{3+}$ emitting states, we did not observe emission from 2.

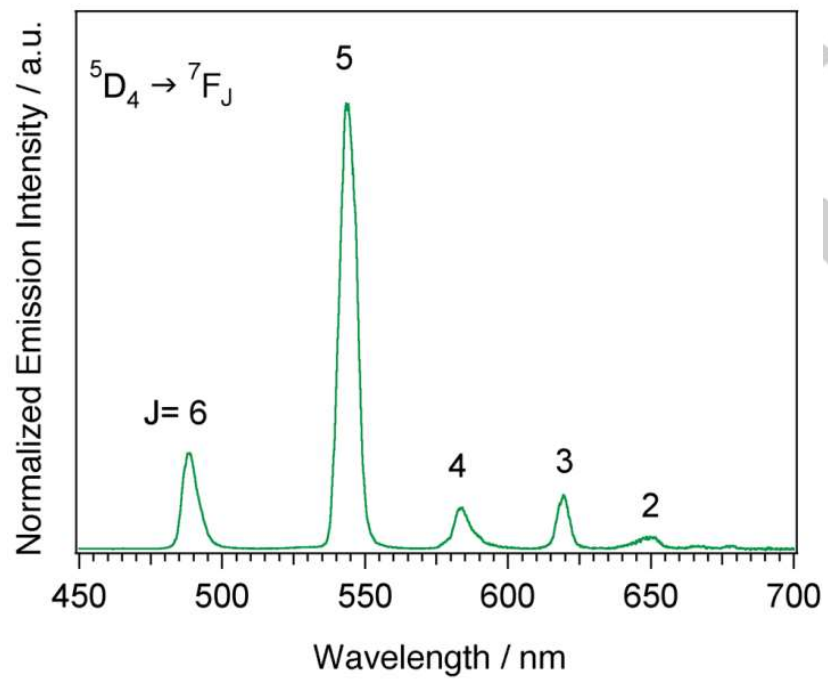

Figure 11. PL spectra of 5 complex excited at $350 \mathrm{~nm}$.

On the other hand, green emission detectable at naked eye were achieved from complex 5 (Figure 11).

\section{Conclusions}

The reaction between lanthanide $\beta$-diketonato complexes $[\operatorname{Ln}(\beta$ dik $\left.)_{3}\right](\mathrm{Ln}=\mathrm{Eu}, \beta$-dik $=\mathrm{hfac}, \mathrm{dbm}, \mathrm{tta} ; \mathrm{Ln}=\mathrm{Tb}, \beta$-dik $=\mathrm{hfac}$, $\mathrm{dbm}$ ) with the heterotopic ligand bipyMO carried out in toluene afforded the 9-coordinated $\left[\mathrm{Ln}_{2}(\mathrm{hfac})_{6}(\text { bipyMO })_{3}\right]$ and 8coordinated $\quad\left[\mathrm{Ln}_{2}(\mathrm{dbm})_{6}(\text { bipyMO })_{2}\right], \quad\left[\operatorname{Ln}_{2}(\mathrm{tta})_{6}(\text { bipyMO })_{2}\right]$ derivatives. The large difference in affinity towards nitrogen and oxygen donors dictates for lanthanides the outcome of reaction.

All the complexes have good emission properties with PLQY value up to $44 \%$.

The rigid ligand bipyMO is able to bridge two lanthanide centres exclusively through the oxygen atom leaving a pendant uncoordinated nitrogen function available for further reactions like for example the formations of $3 d-4 f$ heterometallic coordination polymers. In the CPs the perfect alternation of the metallic centres is possible thanks to the efficient discrimination operated by bipyMO.

Basic synthetic information gained is useful for the preparation of heterometallic compounds that can be formed both using molecular complexes as building blocks or by self-assembling strategies.

\section{Experimental Section}

Materials and Instrumentation. $\left[\mathrm{Ln}(\beta-\mathrm{dik})_{3}\right]$ and $\left[\mathrm{Ln}(\beta-\mathrm{dik})_{3}\left(\mathrm{H}_{2} \mathrm{O}\right)_{2}\right](\mathrm{Ln}=$ $\mathrm{Eu}, \mathrm{Tb}, \beta$-dik $=\mathrm{hfac}, \mathrm{dbm} ; \mathrm{Ln}=\mathrm{Eu}, \beta$-dik $=\mathrm{tta}),{ }^{[17,18]}$ and bipyMO $2 \mathrm{H}_{2} \mathrm{O}^{[6 a]}$ were prepared according to the literature.

FTIR spectra in the solid state were recorded with a Perkin-Elmer "Spectrum One" spectrometer, with ATR technique. Elemental analyses $(\mathrm{C}, \mathrm{H}, \mathrm{N})$ were performed at Dipartimento di Chimica e Chimica Industriale, Università di Pisa. The luminescence spectra were recorded on solid samples at room temperature in a front-face acquisition geometry with a spectrofluorimeter (Fluorolog-3, Horiba JobinYvon) equipped with double-grating monochromator in both the excitation and emission sides coupled to a R928P Hamamatsu photomultiplier and a $450 \mathrm{~W}$ Xe arc lamp as the excitation source. The emission spectra were corrected for detection and optical spectral response of the spectrofluorimeter supplied by the manufacturer. The excitation spectra were corrected for the spectral distribution of the lamp intensity using a photodiode reference detector. The luminescence lifetimes in the microsecond-millisecond scales were measured by a pulsed Xe lamp with variable repetition rate and elaborated with standard software fitting procedures. The experimental uncertainty on $\tau$ values is $\pm 10 \%$. Absolute photoluminescence quantum yields (PLKY) were calculated by corrected emission spectra obtained with an apparatus consisting of a Spectralon coated integrating sphere accessory (4", F-3018, Horiba Jobin Yvon), fitted in the fluorimeter sample chamber. For each compound, three independent measurements were carried out, with an estimated error of $\pm 20 \%$.

Syntheses

$\left[E u_{2}(\mathrm{dbm})_{6}(\text { bipyMO })_{2}\right]$, 1. A suspension of $\left[\mathrm{Eu}(\mathrm{dbm})_{3}\right](0,300 \mathrm{~g}, 0.37$ $\mathrm{mmol})$ ) and bipyMO $(0.060 \mathrm{~g}, 0.35 \mathrm{mmol})$ in anhydrous toluene $(25 \mathrm{~mL})$ was refluxed for $2 \mathrm{~h}$. The yellow solution was slowly cooled to $-20^{\circ} \mathrm{C}$. A crystalline solid precipitated out that was decanted and dried in vacuo for 4h. Crystals lose solvent, when dried, converting to an amorphous powder $\left(0.290 \mathrm{~g}\right.$, yield $81.1 \%$ as $\left[\mathrm{Eu}_{2}(\mathrm{dbm})_{6}(\text { bipyMO })_{2}\right]$. El. Anal. Calcd for $\left[\mathrm{Eu}_{2}(\mathrm{dbm})_{6}(\mathrm{bipyMO})_{2}\right], \mathrm{C}_{110} \mathrm{H}_{82} \mathrm{Eu}_{2} \mathrm{~N}_{4} \mathrm{O}_{14}, \%: \mathrm{C}, 66.5 ; \mathrm{H}, 4.2 ; \mathrm{N}, 2.8$ Found: C, 66.2; H, 4.0; N, 2.6. IR-ATR (range: $1700-700 \mathrm{~cm}^{-1}$ ): $1593 \mathrm{~m}$, $1548 \mathrm{~m}, 1514 \mathrm{~m}, 1477 \mathrm{~m}, 1456 \mathrm{~m}, 1411 \mathrm{~m}, 1392 \mathrm{~m}, 1306 \mathrm{~m}, 1284 \mathrm{w}, 1259 \mathrm{~m}$, 
$1217 \mathrm{~m}, 1178 \mathrm{w}, 1155 \mathrm{w}, 1066 \mathrm{~m}, 1021 \mathrm{~m}, 940 \mathrm{w}, 846 \mathrm{w}, 797 \mathrm{~m}, 745 \mathrm{~m}, 720 \mathrm{~m}$ $\mathrm{cm}^{-1}$.

$\left[\mathrm{Tb}_{2}(\mathrm{dbm})_{6}(\text { bipyMO })_{2}\right]$, 2. A suspension of $\left[\mathrm{Tb}(\mathrm{dbm})_{3}\right](0.500 \mathrm{~g}, 0.60$ $\mathrm{mmol})$ and bipyMO $(0.180 \mathrm{~g}, 1.05 \mathrm{mmol})$ in anhydrous toluene $(31 \mathrm{~mL})$ was refluxed for $2 \mathrm{~h}$. The yellow solution was slowly cooled to $-20^{\circ} \mathrm{C}$. A crystalline solid precipitated out that was decanted and dried in vacuo for $1 \mathrm{~h}$. A second crop of crystalline product was obtained by work up of the filtrate. Crystals lose solvent, when dried, converting to an amorphous powder $\left(0.53 \mathrm{~g}\right.$ overall, yield $88,3 \%$ as $\left[\mathrm{Tb}_{2}(\mathrm{dbm})_{6}(\text { bipyMO })_{2}\right]$. El. Anal Calcd for $\left[\mathrm{Tb}_{2}(\mathrm{dbm})_{6}(\text { bipyMO) })_{2}\right], \mathrm{C}_{110} \mathrm{H}_{82} \mathrm{~N}_{4} \mathrm{O}_{14} \mathrm{~Tb}_{2}, \%: \mathrm{C}, 66.0 ; \mathrm{H}, 4.1 ; \mathrm{N}$, 2.8. Found: $\mathrm{C}, 65.6 ; \mathrm{H}, 4.1 ; \mathrm{N}, 2.9$. IR-ATR (range: $1700-700 \mathrm{~cm}^{-1}$ ) $1594 \mathrm{~m}, 1549 \mathrm{~m}, 1515 \mathrm{~m}, 1477 \mathrm{~m}, 1457 \mathrm{~m}, 1415 \mathrm{~m}, 1391 \mathrm{~m}, 1308 \mathrm{~m}, 1284 \mathrm{w}$, $1260 \mathrm{~m}, 1217 \mathrm{~m}, 1176 \mathrm{w}, 1154 \mathrm{w}, 1067 \mathrm{~m}, 1022 \mathrm{~m}, 941 \mathrm{w}, 848 \mathrm{w}, 809 \mathrm{~m}$, $784 \mathrm{~m}, 749 \mathrm{~m}, 721 \mathrm{~m} \mathrm{~cm}^{-1}$. Recrystallization from toluene afforded crystals of 2. suitable for X-Ray diffraction studies.

$\left[E u_{2}(t t a)_{6}(\text { bipyMO })_{2}\right], 3$. To a solution of $\left[\mathrm{Eu}(\mathrm{tta})_{3}\right](0.290 \mathrm{~g}, 0.36 \mathrm{mmol})$ in anhydrous toluene $(25 \mathrm{~mL})$ bipyMO $(0.060 \mathrm{~g}, 0.35 \mathrm{mmol})$ was added. The yellow suspension was refluxed for $2 \mathrm{~h}$ and then was slowly cooled to RT. A small amount of solid was eliminated by filtration. The pale yellow filtrate was treated with heptane $(30 \mathrm{~mL})$ and cooled to $-20^{\circ} \mathrm{C}$. A finely divided colourless solid precipitated out that was dried in vacuo for $7 \mathrm{~h}\left(0.21 \mathrm{~g}, 60.4 \%\right.$ yield as $\left.\left[\mathrm{Eu}_{2}(\mathrm{tta})_{6}(\text { bipyMO) })_{2}\right]\right)$. El. Anal. Calcd for $\left[\mathrm{Eu}_{2}(\mathrm{tta})_{6}(\text { bipyMO) })_{2}\right], \mathrm{C}_{68} \mathrm{H}_{40} \mathrm{Eu}_{2} \mathrm{~F}_{18} \mathrm{~N}_{4} \mathrm{O}_{14} \mathrm{~S}_{6}, \%$ : C, 41.3; $\mathrm{H}, 2.0 ; \mathrm{N}, 2.8$. Found: C, 40.9; H, 2.0; N, 2.9. IR-ATR (range: $1700-700 \mathrm{~cm}^{-1}$ ): $1620 \mathrm{w}$ $1596 \mathrm{~m}, 1537 \mathrm{w}, 1505 \mathrm{w}, 1471 \mathrm{w}, 1412 \mathrm{w}, 1355 \mathrm{w}, 1304 \mathrm{~m}, 1245 \mathrm{w}, 1229 \mathrm{w}$, $1180 \mathrm{~m}, 1127 \mathrm{~m}, 1083 \mathrm{w}, 1060 \mathrm{w}, 1036 \mathrm{w}, 1015 \mathrm{w}, 991 \mathrm{w}, 947 \mathrm{w}, 934 \mathrm{w}, 859 \mathrm{w}$ 847 w, 814 w, 785m, 767w, 749w, 718w. Crystal suitable to single crystal X-Ray diffraction studies were obtained through diffusion of pentane vapours in a toluene solution of the product.

$\left[E u_{2}(h f a c)_{6}(\text { bipyMO) })_{3}\right]$, 4. To a suspension of $\left[\mathrm{Eu}(\mathrm{hfac})_{3}\right](0.360 \mathrm{~g} ; 0.47$ $\mathrm{mmol})$ in toluene $(25 \mathrm{~mL})$ bipyMO was added $(0.120 \mathrm{~g} ; 0.70 \mathrm{mmol})$. The colourless mixture was refluxed for $2 \mathrm{~h}$. The solution was cooled to room temperature and then at $5{ }^{\circ} \mathrm{C}$. Precipitation of a colourless crystalline solid occurred. The suspension was filtered and the solid was dried in vacuo $\left(0.30 \mathrm{~g} ; 62 \%\right.$ yield as $\left.\left[\mathrm{Eu}_{2}(\mathrm{hfac})_{6}(\text { bipyMO) })_{3}\right]\right)$. El. Anal. Calcd for $\left[\mathrm{Eu}_{2}(\mathrm{hfac})_{6}(\text { bipyMO) })_{3}\right], \mathrm{C}_{60} \mathrm{H}_{30} \mathrm{Eu}_{2} \mathrm{~F}_{36} \mathrm{~N}_{6} \mathrm{O}_{15}, \%$ : C, 34.9; $\mathrm{H}, 1.5 ; \mathrm{N}, 4.1$. Found: C, 34.6; H, 1.5; N, 3.9. IR-ATR (range: $1700-700 \mathrm{~cm}^{-1}$ ): $1663 \mathrm{~m}$, $1650 \mathrm{~s}, 1601 \mathrm{w}, 1556 \mathrm{~m}, 1530 \mathrm{~m}, 1505 \mathrm{~m}, 1482 \mathrm{~m}, 1412 \mathrm{w}, 1349 \mathrm{w}, 1321 \mathrm{w}$, $1251 \mathrm{~s}, 1196 \mathrm{~s}, 1134 \mathrm{~s}, 1097 \mathrm{~s}, 1039 \mathrm{~m}, 950 \mathrm{w}, 860 \mathrm{~m}, 850 \mathrm{~m}, 814 \mathrm{~m}, 796 \mathrm{~s}$, $767 \mathrm{w}, 741 \mathrm{~m}, 719 \mathrm{w} \mathrm{cm} \mathrm{cm}^{-1}$. It is soluble at RT in the usual organic solvent. Recrystallization from toluene afforded crystals of $4 \cdot 3 \mathrm{C}_{7} \mathrm{H}_{8}$ suitable for $X$ Ray diffraction studies. The crystals were treated under atmosphere saturated with toluene to avoid collapse due to the loss of the crystallization solvent.
$\left[\mathrm{Tb}_{2}(\text { hfac })_{6}(\text { bipyMO })_{3}\right]$, 5. A suspension of $\left[\mathrm{Tb}(\mathrm{hfac})_{3}\right](1.260 \mathrm{~g}, 1.62$ $\mathrm{mmol}$ ) and bipyMO $(0.410 \mathrm{~g}, 2.38 \mathrm{mmol})$ in $80 \mathrm{~mL}$ of anhydrous toluene was refluxed for $2 \mathrm{~h}$. The solution was slowly cooled to $-20^{\circ} \mathrm{C}$. A yellow crystalline solid precipitated out that was decanted and dried in vacuo for $1 \mathrm{~h}$. In the course of this treatment crystals collapsed for the loss of crystallization solvent $\left(1.26 \mathrm{~g}, 76,5 \%\right.$ yield as $\left[\mathrm{Tb}_{2}(\mathrm{hfac})_{6}(\text { bipyMO) })_{3}\right]$. El. Anal. Calcd for $\left.\left[\mathrm{Tb}_{2}(\text { hfac) })_{6} \text { (bipyMO) }\right)_{3}\right], \mathrm{C}_{60} \mathrm{H}_{30} \mathrm{~F}_{36} \mathrm{~N}_{6} \mathrm{O}_{15} \mathrm{~Tb}_{2}, \%$ : C, 34.7; $\mathrm{H}$, 1.5; N, 4.1. Found: C, 34.5; H, 1.5; N, 4.1. IR-ATR (range: $1700-700 \mathrm{~cm}^{-}$ $\left.{ }^{1}\right): 1651 \mathrm{~m}, 1601 \mathrm{w}, 1555 \mathrm{w}, 1528 \mathrm{w}, 1505 \mathrm{w}, 1480 \mathrm{~m}, 1411 \mathrm{w}, 1347 \mathrm{w}$, $1251 \mathrm{~m}, 1195 \mathrm{~m}, 1134 \mathrm{~m}, 1097 \mathrm{~m}, 1039 \mathrm{w}, 949 \mathrm{w}, 850 \mathrm{w}, 814 \mathrm{~m}, 795 \mathrm{~m}, 767 \mathrm{w}$, $739 w, 719 w \mathrm{~cm}^{-1}$. Single crystals suitable to check the unit cell through X-ray diffractometric studies were obtained: a 22.808(5), b 16.990(6), $c$ 26.111(7) $\AA, \beta$ 109.32(4) .

\subsection{Single-crystal $X$-ray Diffraction}

Crystals of $\mathbf{3}$ were glued at the end of glass fibers and those of $\mathbf{2}$ and $\mathbf{4}$ were sealed in glass capillaries. The diffractions of $\mathbf{2}$ and $\mathbf{3}$ were studied at room temperature by means of a Bruker SMART Breeze CCD diffractometer equipped with graphite monochromated Mo-K $\alpha$ radiation $(\lambda=0.71073 \AA)$. Those of 4 were analysed with the same wavelength using an Oxford diffraction Xcalibur $3 \mathrm{CCD}$ diffractometer at $T=100 \mathrm{~K}$. The crystal data are listed in Table 4 . All the crystalline samples showed a certain degree of disorder that appeared in rather large diffraction spots and with rapidly decreasing intensity as the diffraction angle increased. Intensity data collections were carried out for all samples within the limits given in Table 4. All the structure solutions were found using the automated direct methods contained in SHELXS-97 program. ${ }^{[19]}$ In the structure solution of $\mathbf{2}$, the disorder concerned the lattice solvent, presumably toluene, which could not be introduced into the model. His contribution was therefore removed through the SQUEEZE procedure contained in the Platon program. ${ }^{[20]}$ In the structure of 2, 3 and 4 the disorder concerned the orientation of the ligands and mainly of their fluorinated moieties. All those groups were introduced in the models as distributed in two limit positions fixing to one the total occupancy of the site. The hydrogen atoms were introduced in calculated positions and refined using the riding convention. The final reliability factors listed in Table 4 suggest that the disorder problems prevented the maximum accuracy in the structural results. The quality of the data allows however some considerations about the coordination geometry of the analyzed compounds. Supplementary crystallographic data for this paper have been deposited with The Cambridge Crystallographic Data Centre and can be obtained free of charge from it. The deposition numbers for each compound are listed in Table 4

Table 4. Crystal data and refinement summaries for 2, 3 and 4.

\begin{tabular}{llll}
\hline Identification code & \multicolumn{1}{c}{$\mathbf{2 \cdot \text { solvent }}$} & $\mathbf{3}$ & $\mathbf{4} \cdot \mathbf{3}$ toluene \\
\hline CCDC number & 1818119 & 1818120 & 1818122 \\
Empirical formula & $\mathrm{C}_{110} \mathrm{H}_{82} \mathrm{~N}_{4} \mathrm{O}_{14} \mathrm{~Tb}_{2}$ & $\mathrm{C}_{68} \mathrm{H}_{40} \mathrm{~F}_{18} \mathrm{~N}_{4} \mathrm{O}_{14} \mathrm{~S}_{6} \mathrm{Eu}_{2}$ & $\mathrm{C}_{81} \mathrm{H}_{53} \mathrm{~F}_{36} \mathrm{~N}_{6} \mathrm{O}_{15} \mathrm{Eu}_{2}$ \\
Formula weight & 2001.63 & 1975.32 & 2338.21 \\
Crystal system & Triclinic & Triclinic & Monoclinic \\
Space group & $P \overline{1}$ & $P \overline{1}$ & $P 2{ }_{1} / n$ \\
$a(\AA)$ & $15.5579(6)$ & $12.0207(3)$ & $21.9239(7)$ \\
$b(\AA)$ & $15.5816(6)$ & $12.5035(3)$ & $16.8603(3)$ \\
$c(\AA)$ & $15.6462(6)$ & $13.7329(3)$ & $25.8917(6)$ \\
$\alpha\left(\left(^{\circ}\right)\right.$ & $100.088(2)$ & $109.3770(10)$ & 90 \\
$\beta\left({ }^{\circ}\right)$ & $107.271(2)$ & $99.8700(10)$ & $109.988(3)$ \\
$\gamma\left({ }^{\circ}\right)$ & $116.020(2)$ & $96.2280(10)$ & 90 \\
Volume $\left(\AA^{3}\right)$ & $3041.7(2)$ & $2461.76(10)$ & $8994.2(4)$ \\
$Z$ & 1 & 1 & 4
\end{tabular}




$\begin{array}{lll}\rho_{\text {calc }}\left(\mathrm{g} \mathrm{cm}^{-1}\right) & 1.093^{*} & 1.738 \\ \mu\left(\mathrm{mm}^{-1}\right) & 1.205^{*} & 1.921 \\ F(000) & 1012^{*} & 972 \\ \theta \text { range }\left(^{\circ}\right) & 2.8 \text { to } 22.6 & 2.7 \text { to } 33.9 \\ \text { Reflections collected } & 35151 & 44125 \\ \text { Independent reflections } & 8022 & 13592 \\ \text { Goodness-of-fit on } F^{2} & 1.080 & 1.247 \\ \text { Final } R_{1}[I \geq 2 \sigma(I)] & 0.0395 & 0.0776 \\ \text { Final } w R_{2}[I \geq 2 \sigma(I)] & 0.1051 & 0.1627 \\ \text { Final } R_{1} \text { [all data] } & 0.0547 & 0.0974 \\ \text { Final } w R_{2} \text { [all data] } & 0.1167 & 0.1745\end{array}$

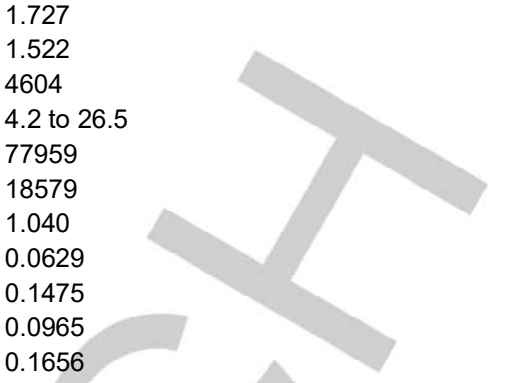

* calculated by neglecting the contribution of the disordered solvent

[6] a) D. J. Hoffart, N. C. Habermehl, S. J. Loeb, Dalton Trans. 2007, 2870 2875; b) O. Toma, N. Mercier, M. Allain, C. Botta, CrystEngComm. 2013, 15, 8565- 8571; c) V. N. Vukotic, S. J. Loeb, Supramol. Chem. 2016, 28, 151-160

\section{Acknowledgements}

[7] V. S. Sastri, J.-C. Bünzli, V. Ramachandra Rao, G. V. S. Rayudu, J. R. Perumareddi in Modern Aspects of Rare Earths and Their Complexes, Elsevier, 2003.

The authors thank the Università di Pisa (Fondi di Ateneo 2014 and 2015 and PRA_2018_23 Materiali Funzionali, Progetti di Ricerca di Ateneo) and Ministero Istruzione Università e Ricerca, MIUR (PRIN 2015 20154X9ATP Progetti di Ricerca di Interesse Nazionale) for financial support.

Keywords: lanthanides • heterotopic ligands • hypodentate ligands • $\beta$-diketonato ligands • photoluminescence • crystal structure

[8] D.-L. Long, A. J. Blake, N. R. Champness, M. Schröder, Chem Commun. 2000, 1369-1370

[9] D.-L. Long, A. J. Blake, N. R. Champness, C. Wilson, M. Schröder Chem. Eur. J. 2002, 8, 2026-2033.

[10] a) C. Seward, S. Wang, Can. J. Chem. 2001, 79, 1187-1193; b) W. X Zhu; J. Coord. Chem. 2002, 55, 251-257; c) S.-L. Ma, W.-X. Zhu, G.-H Huang, D.-Q. Yuan, X. Yan, J Molec. Struct. 2003, 646, 89-94; d) S.-L. Ma, C.-M. Qi, Q.-L. Guo, M.-X. Zhao, J. Molec. Struct. 2005, 738, 99-104 e) X. Yi, G. Calvez, C. Daiguebonne, O. Guillou, K. Bernot, Inorg. Chem. 2015, 54, 5213-5219.

[11] X. Yi, K. Bernot, F. Pointillart, G. Poneti, G. Calvez, C. Daiguebonne, O. Guillou, R. Sessoli, Chem. Eur. J. 2012, 18, 11379-11387.

[12] L. Armelao, D. Belli Dell'Amico, L. Bellucci, G. Bottaro, L, Labella, F. Marchetti, S. Samaritani, Polyhedron 2016, 119, 371-376.

[13] K. Binnemans, Coord. Chem. Rev., 2015, 295, 1-45.

[14] J. C. G. Bünzli, Coord. Chem. Rev., 2015, 293-294, 19-47.

[15] K. Binnemans in Handbook on the Physics and Chemistry of Rare Earths, Vol 35 (Eds.: K.A. Gschneidner, Jr., J.-C.G. Bünzli, V.K. Pecharsky) Elsevier B.V., 2005, 107-272.

[1] K. Biradha, M. Sarkar, L. Rajput, Chem. Commun. 2006, 4169-4179.

[2] R. J. Hill, D.-L. Long, N. R. Champness, P. Hubberstey, M. Schröder Acc. Chem. Res. 2005, 38, 335-348.

[3] a) O. Toma, N. Mercier, M. Bouilland, M. Allain, CrystEngComm. 2012, 14, 7844-7847; b) A. A. Dar, G. A. Bhat, R. Murugavel, Inorg. Chem 2016, 55, 5180-5190; c) O. Toma, M. Allain, F. Meinardi, A. Forni, C. Botta, N. Mercier, Angew. Chem. Int. Ed. 2016, 55, 7998-8002; d) O Toma, N. Mercier, M. Allain, F. Meinardi, C. Botta, Eur. J. Inorg. Chem. 2017; 844-850.

[4] D. Belli Dell'Amico, S. Ciattini, L. Fioravanti, L, Labella, F. Marchetti, C. A, Mattei, S. Samaritani, Polyhedron 2018, 139, 107-115.

[5] L. Armelao, D. Belli Dell'Amico, G. Bottaro, L. Bellucci, L. Labella, F. Marchetti, C. A. Mattei, F. Mian, F. Pineider, G. Poneti, S. Samaritani, Dalton Trans. 2018, 47, 8337-8345.

16] a) G. A. Crosby, R. E. Whan, J. J. Freeman, J. Phys. Chem.,1962, 66, 2493-2499; b) Y. S. Yang, M. L. Gong, Y. Y. Li, H. Y. Lei, S. L. Wu, J. Alloys Compd., 1994, 207-208, 112-114.

[17] a) S.J. Lyle, A.D. Witts, Inorg. Chim. Acta, 1971, 5, 481-484; b) A.I. Voloshin, N.M. Shavaleev, V.P. Kazakov, J. Lumin., 2000, 91, 49-58.

[18] L. Armelao, D. Belli Dell'Amico, L. Bellucci, G. Bottaro, L. Labella, F. Marchetti, S. Samaritani, Inorg. Chem. 2016, 55, 939-947.

[19] G. M. Sheldrick, Acta Crystallogr., Sect. A: Found. Crystallogr., 2008, 64 112.

[20] T. L. Spek, Acta Cryst., 1990, A46, 194-201. 


\section{FULL PAPER}

The heterotopic divergent bipyMO ligand reacts with neutral diketonato lanthanide complexes to yield dinuclear compounds $\quad\left[\mathrm{Ln}_{2}(\beta-\right.$ $\left.\mathrm{dik})_{6}(\text { bipyMO })_{n}\right](\mathrm{Ln}=\mathrm{Eu}, \mathrm{Tb})$ with a pendant nitrogen donor functionality. All the reported complexes have good emission properties with PLQY value up to $44 \%$. These derivatives are potentially useful as building blocks for the synthesis of heterometallic compounds.

\section{Lanthanide metallo-ligands}

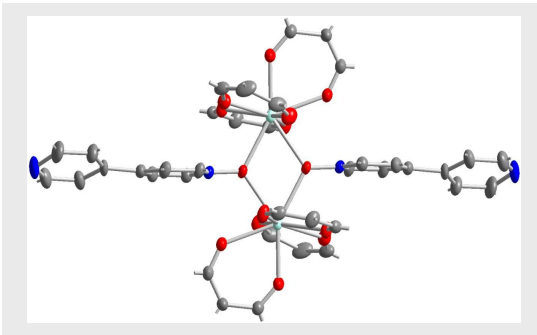

Lidia Armelao, Daniela Belli Dell'Amico, Luca Bellucci, Gregorio Bottaro, Samuele Ciattini, Luca Labella, Giacomo Manfroni, Fabio Marchetti, Carlo Andrea Mattei and Simona Samaritani

\section{Page No. - Page No.}

Lanthanide dinuclear complexes with the divergent heterotopic 4,4'-bipyridine- $N$ oxide (bipyMO) ligand 